\title{
A combined variation of the right urogenital veins and bilaterally renal arteries
}

\author{
E.H. Park' ${ }^{1}$ J. Kim², S.P. Yoon ${ }^{2}$ \\ ${ }^{1}$ Medical Course, School of Medicine, Jeju National University, Jeju-Do, Republic of Korea \\ ${ }^{2}$ Department of Anatomy, School of Medicine, Jeju National University, Jeju-Do, Republic of Korea
}

[Received 21 December 2014; Accepted 22 January 2015]

\begin{abstract}
Variation in urogenital vessels is of interest to clinicians as well as anatomists since it has complex steps of urogenital development. We found 2 right and 3 left renal arteries, double right renal veins, the right testicular artery arisen from the right main renal artery, and the right testicular vein as a tributary of an additional right renal vein in a 57-year-old Korean male cadaver, whose cause of death was 'unknown'. The multiple vascular variations near the renal hilum are detectable in seemingly normal individuals and a deeper understanding of the complicated urogenital vasculature might be very important with its embryogenesis. (Folia Morphol 2015; 74, 3: 399-401)
\end{abstract}

Key words: embryogenesis, urogenital vessels, urogenital rete arteriosum, subcardinal vein, variation

\section{INTRODUCTION}

The renal and gonadal arteries are a pair of lateral branches from the abdominal aorta. The right renal and gonadal vein is a tributary of the inferior vena cava, respectively, whereas the left renal vein receives the left suprarenal and left gonadal veins in addition to that coming from the kidney. Anatomical variation in renal and testicular vessels has been reported in detail because of its importance in surgical, radiologic procedures pertaining to kidney and testis as well as its embryogenesis $[11,14,16]$. Their respective variations have already been reported as individual cases, but the occurrence of combined variations of the urogenital vasculature in a same person need to be reported for understanding the complicated urogenital systems. We observed variations of the bilateral renal arteries, right renal veins and atypical right testicular vessels, which has rarely been described to the best of our knowledge.

\section{CASE REPORT}

During a routine dissection at Jeju National University Medical School in 2013, we observed multiple variations in the renal and testicular vessels in a 57-year-old Korean male cadaver, whose cause of death was 'unknown'.

The right kidney had 2 renal veins of almost equal size, both of which terminated into the inferior vena cava, which occupied $141.6 \mathrm{~mm}$ and $120.0 \mathrm{~mm}$ from the confluence of the common iliac vein, respectively. The higher covered the right main renal artery and the lower crossed the right testicular artery. The lower between the 2 renal veins received the right testicular vein, which ran anterior to the inferior polar artery parallel with the right testicular artery. The renal, suprarenal and testicular veins on the left side were normal (Fig. 1A).

The right kidney received 2 renal arteries $119.7 \mathrm{~mm}$ and $29.0 \mathrm{~mm}$ from the bifurcation of the abdominal

Address for correspondence: Dr S.P. Yoon, MD, PhD, Department of Anatomy, School of Medicine, Jeju National University, 102 Jejudaehak-ro, Jeju-Si, Jeju-Do 63243, Republic of Korea, tel: +82 64 7543823, fax: +82 64 7252593, e-mail: spyoon@jejunu.ac.kr 

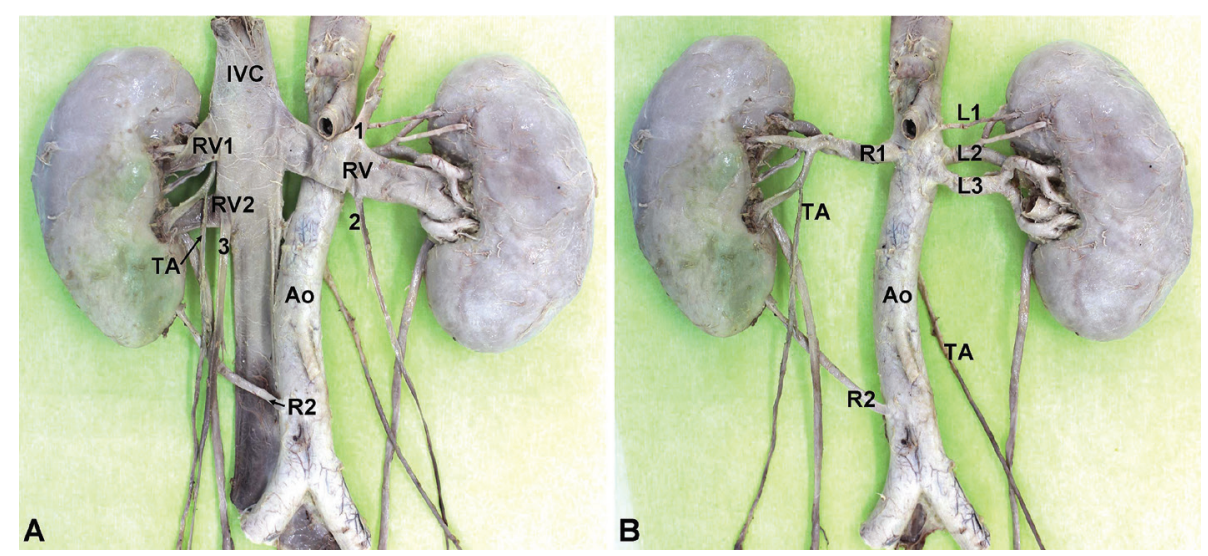

Figure 1. Multiple variations on the renal and gonadal vessels before $(\mathbf{A})$ and after $(\mathbf{B})$ removing the veins. Note the relationship between double right renal veins (RV1 and RV2) and the right testicular vein (3) while left renal vein (RV) received the suprarenal (1) and testicular (2) veins. The renal arteries are designated on the right side R1 to R2 to the lowest and similarly L1 to L3 on the left side. Note the precaval course of the inferior polar artery (R2) and right testicular artery (TA) from the right main renal artery (R1); Ao — abdominal aorta; IVC — inferior vena cava.

aorta, respectively. One of which took its origin from the lateral aspect of the abdominal aorta and its anterior inferior segmental branch gave origin to the right testicular artery, which ran anterior to the $2^{\text {nd }}$ right renal vein. The other, inferior polar artery, originated from the anterolateral aspect of the abdominal aorta, ran with precaval course and terminated into the inferior pole of the right kidney. The left kidney received 3 renal arteries $126.0 \mathrm{~mm}, 115.6 \mathrm{~mm}$, and $108.5 \mathrm{~mm}$ from the bifurcation of the abdominal aorta, respectively. All arose from the lateral aspect of the abdominal aorta just inferior to the origin of superior mesenteric artery (Fig. 1B).

\section{DISCUSSION}

The variations, which are reported here, have already been reported as an individual case of variations, but occurrence of variations of the bilateral renal arteries, right renal veins, and atypical right testicular vessels in the same person have rarely been reported to the best of our knowledge. Similar works previously described the multiple variations associated with malrotated kidneys that had bilateral renal arteries and an additional right renal vein [3] or multiple right renal vessels [6]. Multiple renal vessels associated with the testicular vessels also described as double renal vessels and testicular arteries in left side [8] or multiple right renal vessels directly associated with testicular vessels [13]. The frequent variation on the gonadal artery is a right testicular artery arising from the right renal artery and a left artery with an aortic origin $(2.6-6 \%)[1,17]$.

Variations in the right renal vein (up to $30 \%$ of individuals) are more often reported as compared to the left renal vein $[4,9,16]$. Major variants include the dual renal veins: the lower renal vein of double renal veins was draining into the inferior vena cava indirectly via the upper renal vein $[8,19]$ or a single hilar vein splits into ' $Y$ '-shaped 2 components with an accessory renal artery passing through the space between the inferior vena cava and the 2 components of the right renal vein [10]. Minor variants include the drainage of a gonadal vein into the right renal vein, which was historically described by Zumstein 4 times in 220 observations in the right side [4]. For the right testicular vein, various termination sites have been described including the renal vein $(4.2-7 \%)[5,16]$, the accessory renal vein (1.3\%) [1] and the junction of the vena cava with the renal vein in $12.5 \%$ [5].

The abnormalities in the urogenital artery are frequent, well-described embryological point of view, and so need no further detailed discussion $[7,9,15,16]$. Briefly, mesonephric arteries are divided into cranial, middle and caudal in embryo: the testicular artery normally originated from the caudal group while the middle group gives rise to the renal arteries from the definitive branches of the urogenital rete arteriosum. Variations in the number of urogenital arteries are result from errors in vessel embryogenesis, which are closely related to the double movements including ascending kidneys and descending testes. In the present case, the abnormalities in the urogenital artery might be considered to originate from the middle group of mesonephric arteries, although any of the arteries can become the testicular artery.

Contrary to the arteries, there is vast network of three pair of parallel veins in communication during 
$4^{\text {th }}$ to $8^{\text {th }}$ week: the posterior cardinal veins, the subcardinal veins and the supracardinal veins. The normal testicular veins, the renal veins, and the segments of the inferior vena cava into which the testicular veins drain, have a common origin from the foetal subcardinal vein. The right subcardinal vein becomes the main drainage channel and develops into the renal segment of the inferior vena cava, right renal vein and right testicular vein $[9,11,12,16]$. In this context, variations of the urogenital veins are caused by dysplasia of the subcardinal venous system during embryogenesis. In our case, the right testicular vein derives from the caudal portion of the right subcardinal vein that terminates in the subsupracardinal anastomosis. The drainage of the right testicular vein into the right renal vein is due to shift and migration of termination of the caudal segment of the right subcardinal vein to the right renal vein portion of subcardinal sinus as previously suggested [14].

Variations in the number of urogenital vessels are clinically silent and go unnoticed until they are discovered during a surgical procedure or at necropsy [2], but also appeared in hydronephrosis [13] or entrapment of the left testicular artery [18]. Since the right renal vein may branch prior to its union with the inferior vena cava to let the right testicular artery pass through (4\%) [8], also observed in this case, complex variations in the urogenital vessels might increase the risk of the renal transplantation, varicocelectomy or abdominal/ retroperitoneal vascular operations [11].

Taken together, we found 2 right and 3 left renal arteries, double right renal veins, right testicular artery arisen from the right main renal artery and right testicular vein as a tributary of an additional right renal vein in a Korean male cadaver. To our knowledge, this anatomic variation has rarely been described, although the variations on the multiple renal veins associated with atypical right testicular vein might be clinically silent. The multiple variations in urogenital vessels can be explained by the embryogenesis and a deeper knowledge of the probable congenital anomalies of the urogenital vessels is useful for clinicians as well as anatomists.

\section{REFERENCES}

1. Asala S, Chaudhary SC. Masumbuko-Kahamba N, Bidmos M (2001) Anatomical variations in the human testicular blood vessels. Ann Anat, 183: 545-549.

2. Ballesteros LE, Saldarriaga V, Ramirez LM (2014) Morphological evaluation of the renal veins: a study with autopsy material from Colombian subjects. Rom J Morphol Embryol, 55: 77-81.

3. Bayramoglue A, Demiryurek D, Erbil KM (2003) Bilateral additional renal arteries and an additional right renal vein associated with unrotated kidneys. Saudi Med J, 24: 535-537.

4. Bergman RA, Afifi AK, Miyauchi R (2014) Illustrated encyclopedia of Human Anatomic Variation: Opus II: Cardiovascular System: Veins: Abdomen: http://www. anatomyatlases.org/AnatomicVariants/MuscularSystem/ Text/Veins/RenalSpenicTesticular.shtml.

5. Favorito LA, Costa WS, Sampaio FJ (2007) Applied anatomic study of testicular veins in adult cadavers and in human fetuses. Int Braz J Urol, 33: 176-180.

6. Gao L, Bu S, Wan F, Zhao F, Wei Q, Han P, Fan T, Yang L (2013) An extremely rare case of unilateral renal arterial and venous multiple deformity, combined with duplex pelvis and malrotation. Int Urol Nephrol, 45: 327-332.

7. Jeon YJ, Lee JN, Yoon SP (2014) Bilateral asymmetrical multiple renal arteries associated with the left testicular artery. Folia Morphol, 73: 510-513.

8. Kayalvizhi I, Monisha B, Usha D (2011) Accessory left testicular artery in association with double renal vessels: a rare anomaly. Folia Morphol, 70: 309-311.

9. Kumar S, Neyaz Z, Gupta A (2010) The utility of 64 channel multidetector CT angiography for evaluating the renal vascular anatomy and possible variations: a pictorial essay. Korean J Radiol, 11: 346-354.

10. Lavy M, Martin L, Eouzan D, Turco C, Heyd B, Mantion G, Parratte B. Tatu L (2015) An unusual case of Y-shaped right renal vein. Surg Radiol Anat, 37: 101-104.

11. Mathews R, Smith PA, Fishman EK, Marshall FF (1999) Anomalies of the inferior vena cava and renal veins: embryologic and surgical considerations. Urology, 53: 873-880.

12. McClure CFW, Butler EG (1925) The development of the vena cava inferior in man. Am J Anat, 35: 331-383.

13. Nayak BS (2008) Multiple variations of the right renal vessels. Singapore Med J, 49: e153-e155.

14. Paraskevas GK, Ioannidis O, Natsis K, Martoglou S (2012) Abnormal bilateral drainage of testicular veins: embryological aspects and surgical application. Rom J Morphol Embryol, 53: 635-638.

15. Paraskevas GK, Natsis K, Nitsa Z, Papazioqas B, Kitsoulis $P$ (2014) Bilateral double testicular arteries: a case report and review of the literature. Potential embryological and surgical considerations. Folia Morphol, 73: 383-388.

16. Pérez JA, Torres FG, Toribio AM, Fernández LK, Hayoun C, Naranjo ID (2013) Angio CT assessment of anatomical variants in renal vasculature: its importance in the living donor. Insights Imag, 4: 199-211.

17. Pozniak MA, Balison DJ, Lee FT Jr, Tambeaux RH, Uehling DT, Moon TD (1998) CT angiography of potential renal transplant donors. RadioGraphics, 18: 565-587.

18. Satheesha NB (2007) Abnormal course of left testicular artery in relation to an abnormal left renal vein: a case report. Kathmandu Univ Med J, 5: 108-109.

19. Verma RS. Kalra S, Rana K (2005) Malformation of renal and testicular veins: a case report. J Anat Soc India, 54: 29-31. 